\section{W. Kurt Roth}

Red Cross, Frankfurt, Germany

\title{
The Future Perspectives of Nucleic Acid Testing in the Blood Transfusion Service
}

In the transfusion community, the implementation of nucleic acid testing for viral pathogens such as HIV, HBV, and $\mathrm{HCV}$ is currently under discussion. This method is expected to efficiently close the diagnostic window by detecting viral agents prior to the traditional antibody/antigen immunoassays and thus to improve the safety of the transfusion products. However, in 1996, Schreiber et al. [Schreiber GB, Busch MP, Kleinman SH, Koreliz JJ, for the Retrovirus Epidemiology Donor Study: The risk of transfusion-transmitted viral infections. N Engl J Med 1996;334:1685-1690] concluded in their study that even after implementation of nucleic acid testing, a residual risk for transfusion-associated infections has to be assumed (table 1).

Nucleic Acid Testing at the Hessian Blood Transfusion Service In 1996, the Hessian Blood Transfusion Service Frankfurt decided to introduce PCR testing for the detection of HIV, $\mathrm{HCV}$, and HBV pathogens. As throughput peaks of up to 1,500 samples per day have to be processed in the Frankfurt blood bank, pooling of samples is inevitable with the technologies available at this point of time. The maximum pool size is set at 96 samples, and the detection limit at 1,000 molecules per $\mathrm{ml}$ of the donation. An inhibition control for each PCR is included, and barcode labeling is used for safe sample processing. PCR testing is done in parallel to ELISA testing in order to release the product without delay.

In January 1997, PCR testing of all plasma was started, and in April that of all red cells produced at the institute. Since August $1997,90 \%$ of the institute's platelet concentrates have

Table 1. Residual risk for transfusion-associated infections per million donations

\begin{tabular}{llll}
\hline Method & HIV & HBV & HCV \\
\hline ELISA screening & 2 & 15.8 & 9.7 \\
Nucleic acid testing & 1 & 9 & 2.2 \\
\hline
\end{tabular}

been PCR-tested for all three parameters. In the meantime, approximately 180,000 donations have been tested. The rate of positives has been relatively high because all ELISA reactives are included in the PCR system. HCV PCR positives totalled to 33, all of them antibody positive. There was a total of $16 \mathrm{HBV}$ positives, and a total of three HIV positives in the pool testing. So far, there has not been any donation which was only PCR positive and antibody negative.

The total costs for PCR testing amount to appoximately US\$ 5.0/donation at present, and include pre-PCR pooling, centrifugation (concentration of the virus), extraction, external inhibition control PCR, HIV PCR, HCV PCR, HBV PCR, data interpretation and transfer, as well as overhead. In this context, it has to be pointed out that taking one PCR, for example the HIV PCR, out of this complete process would only reduce the total costs by approximately $10 \%$.

\section{Future Requirements}

Based on the experience of the Hessian Blood Transfusion Service Frankfurt, the future requirements for nucleic acid testing for transfusion screening purposes are as follows:

- integrate closed-tube extraction, amplification and detection in one system;

- significantly reduce detection time from approximately 30 to 5 minutes;

- increase extraction volumes in order to omit centrifugation of pooled samples;

- introduce pierceable caps for pooling to reduce contamination risks;

- cut costs by performing the extraction from whole blood samples to reduce the reagent volumes;

- multiplex PCR allowing for single donor testing to omit pooling and speed up total processing time;

- extend PCR testing to viral pathogens such as HAV, CMV, $\mathrm{HGV}$, and B19.

Ultimately, the development of nucleic acid diagnostics needs to result in a fully automated diagnostic instrument system to satisfy the specific demands of a transfusion laboratory.

\begin{tabular}{ll}
\hline KARGER & $\begin{array}{l}\text { (1) 1998 S. Karger GmbH, Freiburg } \\
\text { Fax (07 61) } 4520714 \\
\text { www.karger.com }\end{array}$
\end{tabular}

This article is also accessible online at: http://BioMedNet.com/karger 